Peer-Reviewed Article

Special Edition | Reflection and Reflective Thinking

(C) Journal of International Students

Volume 10, Issue S2 (2020), pp. 36-50

ISSN: 2162-3104 (Print), 2166-3750 (Online)

ojed.org/jis

\title{
Reflections of Learning Experiences of International Students in Sweden
}

\author{
Liisa Uusimaki \\ University of Gothenburg, Sweden \\ Susanne Garvis \\ Swinburne University, Australia
}

\begin{abstract}
The purpose of this article is to present a qualitative study exploring a small cohort of nine international students' in-depth reflections about their teaching and learning experiences studying at a major Swedish University. Interestingly while there have been numerous studies reporting on the experiences of international students attending Anglo-Saxon universities, few studies have explored teaching and learning experiences of international students studying in Sweden. Using Carol Rodgers (2002) model of four functions of reflections provided a novel way to explore international students' reflections about their learning experiences in Sweden, especially how these are shown in the following different cycles, of presence, description, analysis and experimentation. Making sense of international students' experiences allows us as university lecturers to enhance our understanding how to better support international students' in their learning away from their home universities. A qualitative content analysis was employed to the data collected from 3 focus groups. Findings showed that the international students experienced several cultural and contextual differences from that of their home universities. The differences related to course structures, teaching and learning, as well as the relationship with their Swedish university lecturer(s).
\end{abstract}

Keywords: International students Sweden, reflections, course structure, learning, cultural and contextual differences 


\section{INTRODUCTION}

The Swedish government's international higher education strategy for the period 2020-2030 has as its goal to increase Sweden's attractiveness as a knowledge nation, and to be recognized as a leader of quality education and research (Bladh, 2018). Sweden is a country of interest to many international students and can be seen by the increase in international students' numbers studying in Swedish higher education institutions each year. For example, in the academic year 2018/2019 there was a total of 38330 international students studying in Sweden, these students came from countries such as Germany, France, The Netherlands, China, India, and North America (Swedish Higher Education Authority, (UKÄ), 2020). One reason for the increase may relate to the development of English-taught programs in Swedish higher education institutions, currently there are 1000 English-taught programs on offer across Swedish universities, 100 programs are offered at the postgraduate level and 900 programs are offered at the undergraduate level (see Sweden, (Sverige), 2020).

To date there are few Swedish studies exploring international students teaching and learning experiences in individual courses, rather studies tend to relate to international students' motivations, expectations, and overall cultural experiences studying in Sweden (see Edberg, 2017; Nilsson, 2015; Phang, 2013). Phang (2013) for instance, carried out a qualitative study of eight international teacher education students on their reasons for choosing a Swedish university as their study destination. Three major reasons were identified: 1 ) a positive first impression from the university website that was associated with relevant and interesting information about courses, programs, and a glimpse into the Swedish lifestyle, 2) the university ranking, and 3) the social activities offered by the university. Nilsson (2015) similarly found that the attractiveness of the university website and course offerings were decisive factors why the 116 international students in his study chose Sweden. Edberg (2017) surveyed 7,196 international students on their experiences of internationalization, and, similar to Phang's and Nilsson's studies, found that the reputation of university and the programs offered via the university website were reasons for student choice studying in Sweden. The findings also noted that most students praised the good teaching staff and their English language skills as well as the excellent library (Elibrary) resources.

Interestingly one of the goals and focus of the Swedish international higher education strategy is that all Swedish higher education courses support development of intercultural perspectives among all students. The challenge for university teachers is to not only acquire in-depth knowledge of their subject area from an international perspective, but also to develop pedagogical skills to teach students from different teaching and learning backgrounds and traditions (Bladh, 2018). Based on Rodgers' (2002) model of four functions of reflections, the purpose of this qualitative study is to explore the reflections of a small cohort of international student teaching and learning experiences in Swedish university courses. The purpose is to provide key insights, rather than generalisations. Such insights will provide opportunities to make sense of international student learning, enhance and further develop the pedagogical skills and intercultural competencies of the Swedish University teacher. 


\section{TEACHING AND LEARNING IN SWEDISH HIGHER EDUCATION}

To make sense of international student learning experiences in Swedish courses it is necessary to provide a brief overview (1) how courses are organised and managed in Swedish HE institutions', (2) how the quality of teaching and learning is assured, (3) student teacher relationships, and (4) the purpose of assessment and grading. There are similarities between Swedish course coordination to other universities worldwide for instance, all courses in Swedish HE institutions are organized and managed by course coordinators. Their role involves managing student inquiries, organizing the course content, assessment tasks, and readings. In addition, the role of Swedish course coordinators is to source teaching staff with expertise in both pedagogy and content in a subject or topic offered in courses to ensure high quality teaching and learning (Bladh, 2018). This means that individual courses have several teachers from all levels of academia depending on their expertise e.g. lecturers, senior lecturers, associate professors, full professors, and or Directors of programs. The focus on the scholarship of teaching and learning in Swedish HE today is attributed to a report by the Swedish National Union of Students (SFS) (2014) slamming the poor teaching skills among university teachers and demanding immediate improvement. With a focus on the values of HE democracy, internationalisation, gender equality, equal opportunities and sustainability, all university lecturers are required to attend professional development courses to demonstrate abilities to facilitate and engage all students in critical independent thinking, reasoning, reflection and analysis (Bladh, 2018; Karlsson et al. 2016; SFS 2014).

Informal and personal student-teacher relationship and being on first name basis is common in all Swedish universities and can seem strange to some international students used to a more formal relationship such as addressing academic teaching staff by title and surname. Despite the personal teacher - student relationship there is, however, an expectation that all students take individual or personal responsibility for their learning, which involves self-study.

To ensure time for self-study, it is not uncommon for courses to schedule a lecture one day per week and no lectures for the following two weeks, and the duration of lectures may vary between 2 hours to 4 hours depending on the course and the individual academic. Self-study involves students' organizing time for reading, reflecting, and discussing the literature (books, articles, reports etc.) with peers on campus or online. All Swedish Universities provide a great deal of support, for example, academic language support, counselling and/or mentoring to ensure all students succeed in their study that is free of charge. With a focus on student learning and inclusion, students' voices in Sweden are highly valued and student course evaluations are crucial to improving teaching and learning in courses and programs (Karlsson et al. 2016).

In Sweden, it is a common practice to provide both local and international students several opportunities for re-examination or resubmission of work (Swedish Council for Higher Education (UHR), 2020) as well as choice of assessment. There is no national grading system in Sweden, or an overall grade given for a degree (e.g. GPA) as found in other educational systems, which means that students are not ranked. Grades that are provided at the completion of programs or individual courses 
are, fail (underkänt), pass (godkänt), pass with distinction (väl godkänt), and pass with special distinction (mycket väl godkänt). However, this grading system has been recognized as confusing to international students as it is not compatible with that of their home universities grading systems. To address this dilemma and in line with the European Higher Education Area (EHEA) and the Bologna process (European Commission, 2020) most Swedish universities and university colleges have now implemented the European Credit Transfer and Accumulation System or ECTS (European Commission, 2020) following a 6-point grading system: Excellent (A), Very good (B), Good (C), Satisfactory (D), Sufficient (E) and Fail (F).

\section{THEORETICAL FRAMEWORK}

The theoretical framework in this study is based on the work of Carol Rodgers (2002) and her model of four functions of reflection. While used to support reflection among teachers (see Corrales., Goldberg., Price., \& Turpen, 2020; Eynon \& Gambino, 2016), in this study, we will use the model to explore a small cohort of international students' reflections about their learning experiences studying in Sweden. The ways in which these are shown in the different cycles will improve our understanding as teachers and learners to support international students' learning.

Underlying the four functions of reflections are five principles, firstly, reflection on experiences that relate to personal learning experiences in the classroom. Secondly, reflection as both rigorous and systematic, meaning to slow down the teaching/learning process, to reveal rich and complex details that encourage appreciation, and a way for a considered response rather than a less thoughtful reaction (Rodgers, 2002). The third principle relates to the formation of a community of respect where diverse perspectives are both encouraged and welcomed. The fourth principle is valuing student feedback that is open, honest, and respectful, and finally the fifth principle, student learning as guide to teaching means that in contrast to teaching guiding learning it is learning that guides teaching.

Based on the above principles the four cycles of reflections are: (1) Presence, (2) Description, (3) Analysis and, (4) Experimentation.

(1) Presence.

The first phase of the reflective cycle is being present. It is inclusive of seeing learning, differentiating its parts, giving it meaning, and responding intelligently - in the moment and from moment to moment that together comprise the process of reflection. Rodgers also explains that presence include qualities of love and passion. Love refers to acceptance of the other as a learner and is free of judgment. Passion means not only a passion for the subject matter but for the human endeavour of learning. Passion also relate to both energy and curiosity that keeps one alert to and engaged with a particular situation or person. For instance, international students often choose to study abroad because of their curiosity for learning, whether it is about (as in this study) the Swedish educational system, politics, gender, or about the cultures of their peers.

(2) Description

The process of telling the story of an experience through collaboration. It is in the differentiation and naming of experiences that the diverse elements 
explored together and told from many different perspectives makes learning possible. For example, International students' narratives of diverse educational experiences when explored in collaboration provide opportunities for comparative learning, development of cross-cultural understanding and an awareness about themselves as learners.

(3) Analysis

Generating several different explanations about what is going on and settling on a theory or hypothesis, that one is willing to test in action. This phase according to Rodgers, is where meaning-making happens.

Understanding the self as a learner is an ongoing process of meaning making. Making sense about choosing to study abroad in a country and university vastly different from that of their own countries (e.g. the Swedish University) provided the international students' opportunities making sense of the differences they experienced while learning about who they were as individuals and learners.

(4) Experimentation is about learning to take intelligent action. This cycle follows description and analysis allowing for well thought out and collaboratively constructed theory. For international students, studying in Sweden involves adapting and accepting new ways of learning. For some students it can be challenging, especially when, for example, students' personal learning experiences from their home countries differ to such an extent that new ways of learning in Sweden are perceived as a threat to the self as a learner.

\section{METHOD}

The focus of the study was to explore a small cohort of 9 international students' reflections about their learning experiences at a major Swedish university. The students came from countries such as Australia, Japan, Germany, Belgium, the Netherlands, Macedonia, Spain, France, and Canada, enrolled in a variety of education programmes at the university. These students had not previously studied in Sweden and were unfamiliar with the Swedish culture.

The three 30-minute focus group interviews were audio-recorded and transcribed and analysed based on a qualitative content analysis to make sense of the international students' learning experiences studying in the Swedish university (Bengtsson, 2016; Forman \& Damschroder, 2008). The use of a small sample size as in this study is not aimed at generalization rather it is about uncovering phenomena in context and situation.

In this study, each individual focus group was assigned a code, for example, Focus Group 1 (FG1), Focus Group 2 (FG2) and Focus Group 3 (FG3), students' individual responses were indicated with the line number found in the interview transcription, for example, FG1 10. The interview data from these focus groups were systematically analysed, and broken down into units, such as, Lectures/Seminars/Tutorials, Teaching/Grading and Student-Teacher relationship and assigned the three primary categories or themes. 
(1) Courses. The subcategories that were identified included course content, schedule, and organisation;

(2) Learning and Teaching. The subcategories identified included self-study, assessment, grading;

(3) Relationship with Teachers. The subcategory identified was informal studentteacher relationships.

Thus, the focus of this qualitative analysis was the category system, which was computer-aided with the help of the software for qualitative data analysis MAXQDA in the version Analytics Pro 2018. Working with category systems forms the decisive point of the comparability of the results and thus serves to weigh up the reliability of the qualitative analysis (Forman \& Damschroder, 2008). The final part of the analysis was finding explanation and drawing conclusions. Data were checked within the research team through multiple discussions around categorisation and resulted in a form of reflexivity to support the researchers' awareness of their own biases and possible influences.

\section{Courses}

\section{RESULTS}

All international students' reasons to study at the Swedish university related to its reputation and interest in pedagogy, political studies, comparative education, and particularly, in the areas of special needs and gender education (FG1, FG2, FG3). Some students had chosen courses that aligned to their programs at their home universities and with support from their course coordinator (FG1). Others had relied on the information provided by the university website on the start date and end date of the semester. Course schedules seemed unclear, confusing and "hard to work out" to students who were in Sweden for one semester and needed to be back at the home universities for study commencing second semester (FG1). The problem related to the fact that some courses that began in first semester ran into the beginning of second semester.

Reflecting and comparing the workload at their home universities to that of studying in Sweden most students agreed their workload at home was substantially 'heavier' (FG1, FG3, FG2, 2) as exemplified by a Canadian student:

I have three times like the essays... I have five classes per week and a lot more written exams. We have three written exams per semester per class so that's like 15 exams I have to take like sit down written exams. It's stricter when it comes to essays, referencing, you are not allowed to go in the internet it's only academic journals, peer-reviewed published in the last five years, and the relationship with the teacher too there is no friendship and the classes are a lot bigger ...(FG1, 10)

There were also students who experienced the workload similar to that in their home countries: "I find it quite similar to Australia the only difference is my schedule, so in Australia I do like four units whereas here I am only doing two at a time and then once I finished two I'll do two more (FG 2). There was, however, confusion among students about how the lectures were scheduled, "Lectures are not 
scheduled every week and never in the same room, it's so confusing. I have to check all the time like it takes time" (FG1, 133). This differed from most students' home countries where courses were offered at the same time each year, classes scheduled weekly, at set times, often in the same rooms, and only the lecturer may change (FG1, 131).

Several of the students were aware before their arrival in Sweden that they would have comparatively less workload than at home (FG2, 2). One student had not imagined the free time to be so extreme: "we have only two afternoons, three hours per afternoon or something like that, so it was even more extreme than I expected", (FG3, 18). While other students were initially confused at the free time, "I think it is more relaxed than I thought - like only having two lectures a week, at first, I was really lost because what did you do with the extra time?" (FG2, 16). Students' concern related to a fear of 'missing out' on studies at home (FG2, 74, 76), though this was not the case for all students: a student from Japan explained:

Before I came here, I was expecting that okay this year is going to be kind of a break for me because like you know, in Japan it was a little bit too stressful, because I had to focus on study. I also need to explore other stuff than study. Getting to know more about various cultures, spend more time thinking about my future or just relaxing, thinking, hanging out with friends, so I am happy that I am here now because finally I have free time for myself as well as time for study $(F G 3,27)$.

Reflecting on the positives of the 'free time' some students noted that "it's more like here we learn to how to think critically and that's something I sometimes miss a bit in my (institution)" (FG3, 12). Further, there were students who acknowledged possibilities of concentrating on one or two subjects instead of four, "you have more time for learning it is like a better way for not forgetting it" (FG1, 106). On the other hand, some students identified the free time as problematic, because, compared to their home countries they did not experience learning as much (FG1, 105). A Japanese student reflected on the pros and cons of independent learning:

I am taking two courses...I only go to uni twice a week like, I feel like I have more independence. You have to read and prepare for the class. In Japan, I do pretty much same amount of independent study, reading assignments but I still go to lectures three times a week, for one course. And, well I say they both have pros and cons... personally I wish that I could go to uni more often so that I like keep on studying not only by myself but also with other students, and also I can talk with the professors more often." (FG3, 16).

There was also some discussion about some differences between the Swedish University faculties: "I definitely think it's our maybe our faculty because I know people who are studying biology and they have lots of work to do and here we are just sitting." (FG2, 57).

Students' initial experiences adapting to learning at the Swedish University caused confusion whether relating to understanding the course schedule, locating 
classrooms for each topic or making sense of the so called 'free time' or self-study and the accompanying seemingly light workload. There was a concern among some students about a fear of missing out or falling behind in their study at their home universities. However, as students began to settle in there was a growing appreciation and understanding of the 'free time' especially as it related to independent learning encouraging critical thinking and reflection but also time to interact with other students. The students began to see that in Sweden there is an expectation that each student is responsible for their own learning including preparation for classes and relying on the university learning platform (Canvas) for sourcing information e.g. finding the time and location of classes as well as contact information of support personnel including their course-coordinator.

\section{Teaching and Learning}

While all students had enjoyed the learning, interaction and discussion offered in the courses (FG1, FG2, FG3). There was also disappointment among some students: "I think the courses that we are taking now have a lot of new opportunities (but) they don't get it out of that and we are not stimulated that much. [...] because you can go very deep in some kind of subjects and that's not happening "(FG2, 87).

The compulsory readings preceding lectures were also mentioned, and experienced as not taken seriously by some students (FG2, 89) "whereas I found here it is really interesting to read all that stuff but when we were speaking in our groups it sometimes just (did not) go into that deep." (FG2, 38); and "readings are only rarely referred to during the lectures" (FG3, 30). In contrast, reflecting on group discussions in one course, one student felt "we discuss a lot and I feel like this is the most I have learned, the things I have learned is like, to think about my opinion and to hear the opinions of others and this is something we don't have in Switzerland (FG3, 10). While the students enjoyed sharing perspectives during the small group discussions (FG3, 104), there was a concern about "sharing of opinion" (FG3, 104). One student was particularly critical "I think if it is someone's own opinion then it's just a personal opinion it's not how it is in your country well, it can be but it doesn't need to be"(FG3, 120). There was an agreement among all students about the value of discussions in general "I think it's important to learn how to speak with other people because you have to respect their opinion you have to wait it's your turn to talk or that sort of thing" (FG2, 123). Especially discussions relating to the teaching profession "in education it's very important like because you work with the staff at your school you work with a lot of people when you are a teacher. So I think it's just they want you to get used to that to work with people because you're going to do that your whole career" (FG1, 186).

There was an agreement among all students that the examinations tasks differed significantly from their home universities, "a big difference between the Netherlands and Sweden and something I really like is that we are able to choose our own topic for the essay. In the Netherlands, you have one topic and all 30 students are writing about the same thing" (FG3, 29); and "Students experienced less pressure to compete with each other being encouraged to share ideas" (FG3, 135). In particular there was an appreciation for opportunities to resubmit assignments whereas, "In Japan if you don't submit by the deadline that's your fault and then you fail and they 
never give you second chance. Here you can take final exams several times that never happens in my country" (FG3 150). While most students agreed about the positives of the Swedish system there were also students $(\mathrm{FG} 3,162)$ reflecting on the positives of the traditional system where competition was a motivating factor to get better grades and exemplified by the following response:

"Competition comes with pressure and excitement but it comes with achievement, a bigger feeling of like: wow I am proud of myself you know when you get that 90 and you've worked for it you're like: yes! (FG1 221)

Reflecting on the pass and fail system several students agreed that the knowledge of passing subjects was relatively easy (FG1, 213, FG2, 140), "and it can be a bit demotivating... like why would I bother studying a lot when you know I can pass and it doesn't matter. At home I am always fighting for the highest grade" (FG2, 140). Another problem with passing or failing subjects related to fairness: "if you put a lot of effort in something and someone else doesn't and you get the same grade, so I am not sure what think about that" $(\mathrm{FG} 2,137)$. An alternative perspective related to the importance of feedback as explained by an Australian student:

if you're getting the right feedback as well. [...] like if you're just getting pass or fail and then that's it then you don't really know what you're improving on you just know you've passed of failed without any feedback so if you're getting the right feedback then like it's fine in my opinion. (FG1, 214).

There is no doubt that when relating to examinations or assignments students felt less pressured (FG3, $131 \& 150)$ and they experienced a sense of community with their peers (FG3, 133-135). Nevertheless, the pass and fail system seemed to decrease the motivation and effort among some students knowing that to pass was relatively easy. Nonetheless, what stood out for all students was the support offered at the university and explained by a Japanese student:

... The faculty is here to help you if you have problems you can have support, if you have to write something you can also have access to all the libraries you have always a solution when you have problem ... so, I am not stressed at all about my studies. Whereas in my country I am very stressed about everything, like grades, if I am going to have a spot in the library because there are too many people or if I am going to have some help from my teacher because they don't care about you because there are too many students (FG2, 78).

The main differences and challenges learning in Sweden and agreed by most students related to the focus placed on group work, collaboration and open discussions. For non-English students, reading academic articles in English was particularly stressful. In Sweden there is a requirement for all students to read the required literature attached to each course that include, for example, book chapters, reports, and research articles. To support students to successfully pass the assessment 
or exams in courses there are hours set aside for self-study or what international students refer to as 'free time' this time is to be used for reading and reflecting about the literature. The student-centred learning experiences, where collaboration, discussions and opportunities for students to openly voice their opinions, made some students feel initially quite uncomfortable. Some students suggested that opinions did not relate to 'deep' scholarly learning. Others enjoyed the opportunity to voice their thoughts and to be able to pose questions. The purpose of the open discussions, collaboration and reflection became clear when students learnt that they were able to choose their own topic to write about for the assessment task.

Choosing their own topic is important as it both motivates the students and it is a way that they feel responsible and part of the learning process (Pereira, Niklasson, \& Flores. 2017). All students were surprised to be able to discuss their topics and essays with their peers thus recognizing the benefit of coming together as a community of learners rather than being in competition with each other. The assessment task supported students in confidence building as they were further developing their research skills and especially realizing that the assessment task provided not only deeper and more meaningful learning, but it aligned to the course objectives. Students requiring extra time to submit their essays were surprised at the ease with which they were granted extensions and that there was no penalty or cost involved. The Swedish grading system caused a great deal of discussion among all international students. Some students preferred the traditional system found in their home universities where competition and striving for high grades was both motivating and fun, others were critical of the stress and anxiety that it caused. One student believed that when provided with constructive and fair feedback a grade was not that important; after all it is all about learning, and making mistakes is an integral aspect of the learning journey.

\section{Relationship with Academic Teachers}

Most students found the Swedish academic teachers both personable and open to discussions, "I think teachers in Sweden are not afraid to critique, not afraid to like say the real thing and I really appreciate that about the professors" (FG1, 153). Nonetheless, experiencing having several academic teachers teaching in a course was "weird" (FG1, 90), because most students were used to the one academic teacher "the whole semester... here they change" (FG1, 94). The positives of having several academic teachers related to their expertise in the topics they taught, while the negatives related to not being able to form closer relationships, "I think the biggest problem with having a relationship with the teacher here is that you only see him like once or twice. Like you see him for two lessons and then you don't see him again, whereas in Australia you're with him for a semester, so you get a closer relationship from the start to the end" $(\mathrm{FG} 1,155)$.

To address the academic teachers by their first name was uncomfortable for several students; some students found it disrespectful, and others found it uncomfortable (FG1, 162, FG2, 96, 98, 102). However, students from the Netherlands were used to addressing academic teachers by their first name:

I have heard some people they were like: oh I've never done that before and for me that's very normal because we do it all the time and that creates, yes, 
The consensus among most students was wanting to be taught by academic teaching staff who were enthusiastic, knowledgeable in their topics, approachable, patient and who encouraged and supported students in their learning (SFS, 2014; Karlsson et al. 2016). The fundamental values of higher education in Sweden are democracy, internationalisation, gender equality, equal opportunities, and sustainability. These values underpin and reflect the professional approach to academic teaching and relationships with the students. Swedish academics' informal relationships where students address them by their first name is common in Sweden and clearly confusing to some of the international students. Similarly, unsettling was not having the one and same academic teacher teaching the entire course. This may relate to differences in how learning is perceived in Sweden: that is, learning is the student's personal responsibility, and it is up to the student to initiate contact with academic teaching staff. The casual, friendly and openness of the Swedish academic teachers is reflective of most academic teaching staff. However, there are also Swedish academic teachers who are conservative in nature, who use teacher led approaches where the focus is on teacher talk, rather than student centred learning that encourages discussion, collaboration and relationship building.

\section{DISCUSSION}

The lack of small-scale qualitative studies about international student learning experiences in courses in Sweden is often at the cost of quantitative studies that seldom provide the necessary information to support understanding how to support student learning and how to improve teaching skills. In this study Rodgers' (2002) four functions of reflection provided a useful model for understanding international students' learning experiences in different courses at the Swedish University. The model aligns well with the Swedish perspective where reflection on teaching and learning, student-teacher relationships and in particular the centrality of students' voice are central in the improvement of teaching and learning in programs and courses (SFS, 2014; Karlsson et al. 2016). For example, from students' reflections. Feedback suggested improving the university webpages course information such as, clarifying course schedules grades, and self-study.

The four cycles of reflection related to presence, description, analysis and experimentation (Rogers, 2002):

\section{Presence-Entry into the cycles of reflection}

International students' entry into the cycle of reflection began before their arrival to Sweden. There were several decisions to consider, for examples, their reason and choice of Sweden, the city, the university and the course or courses. Once decisions were made the process of reflection continued together with a curiosity and growing excitement about possibilities for future aspirations, personal growth and sense of self, new learning, ability to adapt to a new country, culture and learning environment as well as making friends.

The evidence of presence related to the international students' curiosity and interest to learn about Sweden, the university culture and about differences between 
Swedish teaching and learning to that of their own countries. Students were both committed to learning and willing to adapt to the Swedish University learning culture. While students' reflections suggested initial confusion and stress adapting to the university culture, teaching and learning methods, student-teacher relationship and with several teachers teaching in the course their overall learning experiences after completion of courses were both positive and encouraging.

There was acknowledgment of the Swedish academic teachers' expertise in their topic areas. Their approach was inclusive with a focus on student learning. In particular, their abilities encouraging collaboration, open discussions and group work differed from students' home universities where traditional teaching methods were the norm, for example, teaching and learning is traditional based on teacher talk, information transference from a set text that students are required to learn (LindblomYlänne, Trigwell, Nevgi, \& Ashwin, 2006). Secondly, students' experiences of selfstudy, initially confusing, was received favorably by all students especially after realizing that the so-called free time was meant to be used for reading, reflection, and discussion with peers to allow deep learning.

2\&3. Describing and analyzing challenges - Reflecting on the learning experiences

The reorganization and reconstruction of learning experiences through sharing stories was important to students' meaning making and to their sense of self as learners. The small focus groups provided all students opportunities to openly, honestly and critically discuss and share their stories of learning without feeling judged.

International students' challenges adapting to the Swedish university culture was initially described as a confusing time, especially in comparison to their home universities and related to course schedules, teaching and learning approaches, different academic teachers in courses and the free time between lectures. However, while there were students preferring their home universities' organization of courses with set schedules, teacher led lectures with the same academic teacher teaching in all topics, there was recognition of the expertise brought by the different academic teachers in Sweden to their learning. There were also students who believed that missing from their home universities were invitations by the lecturer to engage and provide critical discussions, as indicated by one Australian student comparing lectures at the home university to that of high-school classes.

Discussions about the informal relationships and being on first name with Swedish academic teachers were described as unusual and experienced as uncomfortable by some students. One student, mentioned the difficulty using academics' first names in Sweden and was confused by the friendly and open studentteacher relationship, although this did not relate to all Swedish academics. In contrast to Sweden, the culture at most students' home universities did not encourage students to address academic by their first name, as it was a sign of disrespect.

There were students with a preference for traditional teacher-led methods of teaching and learning to that of the Swedish student-centered approach where discussions, collaboration, and group work is the norm. For example, group work for some of the students meant working towards a common goal, that is, the groups in classes had the same goal, with each group member assigned a particular task to complete. In contrast, group work in Sweden meant students collaborated in choosing 
a topic of interest and shared the responsibility for organizing their group work without interference from the academic teacher.

\section{Experimentation - Self-study and Learner centered examination}

The initial confusion about the free time between lectures began to make sense to students as they began to adapt to the Swedish learning culture. They learnt that the free time meant time for independent learning or self-study and how they chose to use the time was entirely up to them. Students came to realize the value of self-study in having enough time to read the vast amount of readings (e.g. journal articles, books, reports) they were required to have read to pass the examinations of courses. This was very different from reading one book over 13 weeks as required at their home universities.

The most mentioned and discussed by all the students, related to the learning-centered examination tasks (Pereira, Niklasson, \& Flores, 2017) that allowed students to choose a topic based on their personal interest areas and responsibility for their own learning (see Sweden, Sverige, 2020). The examination task supported students' meaning-making and deeper learning in their ongoing intellectual development as learners. To support student learning, both oral and written feedback from examiners are common in Sweden and most courses offer opportunities to resubmit for students who receive a fail grade.

The student-centered learning culture in Swedish higher Education (Lindblom-Ylännea et al., 2006) is about supporting students' ongoing development as learners, encouraging both confidence and self-efficacy (Bandura, 1997; Uusimaki, Garvis \& Sharma, 2018). This also means and involves developing trusting relationships, respecting and acknowledging students' capabilities as learners.

\section{IMPLICATIONS}

In this study, Rodgers' (2002) reflective study was used as the theoretical framework to provide new meanings to the international student reflections in Sweden. This study provided also new understandings about international student learning experiences in Sweden and thinking about how institutions can further improve in supporting student learning. In particular, the phase of presence is highly important for the set-up of learning approaches. We suggest it is important that transition periods and workshops are possible to support international students with acculturalization into Swedish higher institutions. In particular, a focus is needed on the different organization of courses and the expectations of students around the delivery and tasks implemented within Swedish classes. This also extends to an understanding around different types of examinations and explaining the different relationships with academic teachers. Our small group of participants have given us some insights into particular areas of need for further investigation.

Based on this qualitative study we suggest two key areas for further reflection:

1) Orientation is needed not only about general information within the university, but also on the actual differences in course delivery in Sweden. This could be the introduction of workshops at the start of courses around identified differences.

2) Course leaders of the Swedish international courses must also be aware of cultural differences in learning (Uusimaki, 2018). In particular, they must 
ensure academic teaching staff teaching in topics are qualified to provide differentiated support to international students, based on their learning needs.

Finally, we also advocate for increased research on international student learning experiences in Sweden. This study has helped fill a small part of the current void in literature. We suggest that more research is needed on student integration and allowing better transitions within learning approaches, especially under these exceptional times of covid-19.

\section{REFERENCES}

Bandura, A. (1997). Self-efficacy: The exercise of control. Freeman.

Bladh, A. (2018). Internationalisation of Swedish higher education and research. https://www.government.se/informationmaterial/2018/02/internationalisation-of-swedish-higher-education-andresearch--a-strategic-agenda/

Bengtsson, M. (2016). How to plan and perform a qualitative study using content analysis. Nursing Plus Open, 2(C), 8-14. https://doi.org/10.1016/j.npls.2016.01.001

Corrales, A., Goldberg, F., Price, E., \& Turpen, C. (2020). Faculty persistence with research-based instructional strategies: A case study of participation in a faculty online learning community. International Journal of STEM Education, 7(21), 1-15. https://doi.org/10.1186/s40594-020-00221-8

Edberg, J. (2017). Internationella studenter tycker till om sin studietid. https://www.gu.se/alumn/nyheter-alumn/Nyheter_detalj//internationellastudenter-tycker-till-om-sin-studietid.cid1433944

European Commission. (2020). The European higher education area Bologna process implementation report 2018. https://eacea.ec.europa.eu

Eynon, B., \& Gambino, L. M. (2016). Professional development for high-impact eportfolio practice. Peer Review, 18(3), 4-8.

Forman, J., \& Damschroder, L. (2008). Qualitative content analysis. Oxford, U.K.: Elsevier.

Karlsson, S., Fjellström, M., Lindberg-Sand, Å., Scheja, M., Pålsson, L., Alvfors, J., \& Gerén, L. (2016). Högskole-pedagogiskutbildning och pedagogisk meritering som grund för det akademiska lärarskapet. Sveriges universitets och högskoleförbund (SUFH). https://suhf.se/publikationer/rapporter/

Lindblom-Ylänne, S., Trigwell, K., Nevgi, A., \& Ashwin, P. (2006). How approaches to teaching are affected by discipline and teaching context. Studies in Higher Education, 31(3), 285298. https://doi.org/10.1080/03075070600680539

Nilsson, P. (2015). Expectations and experiences of inbound students: Perspectives from Sweden. Journal of International Students, 5(2), 161-174. https://doi.org/10.32674/jis.v5i2

Pereira, D., Niklasson, L., \& Flores, M. A. (2017) Students' perceptions of assessment: a comparative analysis between Portugal and Sweden, Higher Education, 73(1), 153-173. https://doi.org/10.1007/s10734-016-0005-0 
Phang, S. L. (2013). Factors influencing international students' study destination decision abroad. GUP Göteborgs Universitet, Gothenburg, Sweden.

Rodgers, C. (2002) Seeing student learning: Teacher change and the role of reflection. Harvard Educational Review, 72(2), 230-253.

Statistical Central Byrån (SCB). (2019). Universitet och högskolor Internationell studentmobilitet $i$ högskolan 2018/19. https://www.scb.se/

Swedish Council for Higher Education, (UHR) (2020). https://www.uhr.se/en/start/

Swedish National Union of Students, (SFS). (2014) Recommendations on general learning outcomes for the teaching qualifications required for employment as academic teacher and on mutual recognition. Retrieved from: https://suhf.se/app/uploads/2019/03/REK-2016-1-On-general-learningoutcomes-for-teaching-qualifications Dnr-024-16.pdf

Swedish Higher Education Authority (UKÄ). (2020). Higher Education Institutions in Sweden. 2020 Status Report. https://english.uka.se/aboutus/publications/reports--guidelines/reports--guidelines/2020-08-26-highereducation-institutions-in-sweden---2020-status-report.html

Sweden, (Sverige) (2020). Highly ranked universities. https://sweden.se/society/higher-education-and-research/

Uusimaki, L. (2018). Teacher Agency. Relational Cultural Theory. In Maurizio Sibilio and Paola Aiello (ed) Lo sviluppo professionale dei docenti. Ragionare di agentività per una scuola inclusive (pp.209-305). Edises Uusimäki, L., Garvis, S., \& Sharma, U. (2018). Swedish final year early childhood preservice teachers' attitudes, concerns and intentions towards inclusion. International Journal of Special Needs Education. DOI: https://doi.org/10.9782/17-00034

\section{BIOGRAPHIES}

Liisa Uusimaki, is an Associate Professor in Pedagogy at the Department of Education and Special Needs Education at the University of Gothenburg, Sweden. Based on her interest and expertise in teaching and learning in higher education she received an Excellent Teacher award in 2018. Her teaching and research areas include; internationalisation, pedagogical and educational leadership, inclusion, identity, mentoring, professional development and developmental psychology. Email: liisa.uusimaki@gu.se

Susanne Garvis is a Professor of Education and the Chair of Department of Education at Swinburne University of Technology. She has extensive experience working within early childhood education around the areas of policy, quality and learning. Her work has also focused on teacher education and the importance of inclusive and democratic ways of working. Email: sgarvis@swin.edu.au 